\title{
EFFECT TO MOTIVATION AND WORK EXPERIENCE IN THE PERFORMANCE OF EMPLOYEES PT. PERKEBUNAN NUSANTARA II (PERSERO) TANJUNG MORAWA
}

\section{Aulia Indra \\ Dosen Tetap Sekolah Tinggi Ilmu Ekonomi Labuhan Batu, Indonesia}

\author{
Auliaindra91@gmail.com
}

\begin{abstract}
Motivation of employees in an organization can be considered simple and can also be a complex problem, because basically humans easily motivated by giving what is his desire. Problems employee motivation can be difficult to determine what remuneration which is considered essential for one is not necessarily important for others. With the motivation to work, it can be seen the effect of the performance of the employee in which the employee will act on the basis kainginan to excel and gain higher positions in the company. The purpose of this research is to analyze the influence of motivation and work experience to employees performance at PT. Perkebunan Nusantara II (Persero) Tanjung Morawa. This research is a quantitative correlation study. The population in this study was 452 and sampled is 82 people. Data collection techniques used through interviews, documentation and questionnaires. The analytical method used is multiple linear regression.

The results showed that in partial motivation $\left(X_{1}\right)$ but not significant effect on employee performance $(Y)$. Partial variable work experience $\left(X_{2}\right)$ positive and significant impact on employee performance $(Y)$. Simultaneously motivation variable $\left(X_{1}\right)$ and work experience $\left(X_{2}\right)$ positive and significant impact on employee performance $(Y)$. The coefficient of determination of $37 \%$ indicates that the motivation $\left(X_{1}\right)$ and work experience $\left(X_{2}\right)$ as the independent variables are able to explain the variable performance of employees, while the remaining $63 \%$ is explained by other factors that are not included in this study.
\end{abstract}

Keywords: motivation, work experience, employee performance

\section{PENDAHULUAN}

\section{Latar Belakang Penelitian}

Sumber daya manusia merupakan aset utama bagi organisasi yang menjadi perencana dan pelaku aktif berbagai aktivitas dalam organisasi. Sumber daya manusia mempunyai pikiran, perasaan, keinginan, status dan latar pendidikan yang pola pikirnya dapat dibawa ke dalam suatu lingkungan organisasi. Sumber daya manusia bukanlah seperti uang, mesin, dan material yang sifatnya positif dan dapat diatur sepenuhnya dalam mendukung tercapainya tujuan perusahaan.

Motivasi kerja karyawan dalam suatu organisasi dapat dianggap sederhana dan dapat pula menjadi masalah yang kompleks, karena pada dasarnya manusia mudah untuk di motivasi dengan memberikan apa yang menjadi keinginannya. Masalah motivasi kerja dapat menjadi sulit dalam menentukan imbalan dimana apa yang di anggap penting bagi seseorang belum tentu penting bagi orang lain. 
Dengan adanya motivasi kerja maka dapat dilihat pengaruhnya dari kinerja karyawan dimana karyawan akan melakukan tindakan atas dasar kainginan untuk berprestasi dan memperoleh jabatan lebih tinggi di perusahaan.

Menurut Luthans (2006), "Motivasi adalah proses sebagai langkah awal seseorang melakukan tindakan akibat kekurangan secara fisik dan psikis atau dengan kata lain adalah suatu dorongan yang ditujukkan untuk memenuhi tujuan tertentu". Apabila nilai ini tidak terjadi, maka akan terwakili individu-individu yang mengeluarkan tingkat biaya tinggi, yang sebenarnya berlawanan dengan kepentingan organisasi. Lemahnya kinerja karyawan sebagai buntut dari kurangnya motivasi yang di berikan kepada karyawan. Fenomena yang terjadi di PT. Perkebunan Nusantara II (Persero) Tanjung Morawa adalah kurangnya motivasi karyawan dalam bekerja yang disebabkan masih adanya pemilihan untuk menduduki suatu jabatan tidak dari prestasi kerjanya yang dinilai, akan tetapi dinilai berdasarkan kedekatan hubungan antara pimpinan dengan bawahan. Hal inilah yang menyebabkan masih kurangnya motivasi karyawan dalam bekerja secara maksimal sehingga mempengaruhi kinerja karyawan secara keseluruhan.

Di PT. Perkebunan Nusantara II (Persero) Tanjung Morawa, pengalaman kerja kadang kurang dibutuhkan untuk menduduki jabatan tertentu, hal ini disebabkan karena kurangnya kepercayaan pimpinan terhadap bawahan yang tidak mempunyai titel atau gelar dari disiplin ilmu yang telah ditentukan. Walaupun karyawan tidak mempunyai pengalaman kerja akan tetapi mempunyai gelar dari disiplin ilmu tertentu, maka bisa mendudukinya karena secara kasat mata tentu karyawan tersebut lebih ahli dibandingkan yang tidak mempunyai gelar. Karena hal tersebut, maka karyawan yang mempunyai pengalaman kerja yang lebih akan tetapi tidak mempunyai gelar tidak tertarik sehingga menyebabkan kinerjanya secara tidak langsung juga ikut menurun.

Berdasarkan uraian tersebut di atas, maka penulis memilih judul :"Pengaruh Motivasi dan Pengalaman Kerja Terhadap Kinerja Karyawan Pada PT. Perkebunan Nusantara II (Persero) Tanjung Morawa”.

\section{KAJIAN PUSTAKA}

\section{Pengertian Motivasi}

Menurut Mangkunegara (2013), motif merupakan suatu dorongan kebutuhan dalam diri pegawai yang perlu dipenuhi agar pegawai tersebut dapat menyesuaikan diri terhadap lingkungannya, sedangkan motivasi adalah kondisi yang menggerakkan pegawai agar mampu mencapai tujuan dari motifnya. Robbins (2007), mendefinisikan bahwa "motivasi sebagai satu proses yang menghasilkan suatu intensitas, arah, dan kekuatan individual dalam usaha untuk mencapai satu tujuan".

Handoko (2013) menyatakan bahwa : "Motivasi di artikan sebagai suatu keadaan dalam pribadi seseorang yang mendorongnya untuk melakukan kegiatankegiatan tertentu guna tercapainya tujuan yang diinginkannya". Dalam melaksanakan setiap pekerjaan seorang karyawan memerlukan suatu perangsang atau motivasi dalam bekerja agar dapat bergairah dan bersemangat dalam melaksanakan pekerjaan tersebut. Dalam hal ini pimpinan selalu menerapkan berbagai strategi atau pedoman untuk meningkatkan motivasi kerja bawahannya dan hal ini tergantung bagaimana seorang pimpinan tersebut bisa mengarahkan 
kegiatan karyawannya menjadi hal yang positif dan terarah demi tercapainya semangat kerja.

\section{Teori Motivasi}

Menurut Hasibuan (2012), teori hirarki dari Maslow (maslow's need hierarchy). Dalam teori ini dikemukakan bahwa ada kebutuhan internal yang sangat mempengaruhi motivasi manusia dalam bekerja. Maslow menyatakan dalam teori ini bahwa kebutuhan manusia itu tersusun dalam suatu hirarki di mana tingkat kebutuhan yang paling rendah adalah kebutuhan fisiologis dan tingkat yang tertinggi adalah kebutuhan aktualisasi diri.

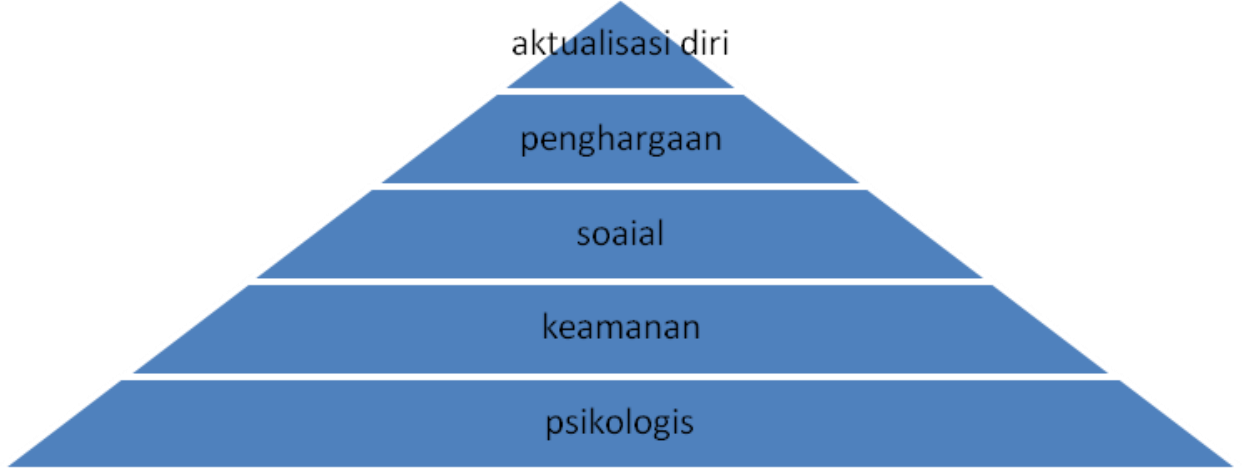

Sumber: Hasibuan (2012).

Gambar II.1. Hirarki Kebutuhan

a. Kebutuhan Fisiologis (fisiological needs)

b. Kebutuhan Keselamatan dan Keamanan (safety and security needs)

c. Rasa Memiliki (belongingness), sosial dan cinta kebutuhan akan teman, afiliasi, interaksi dan cinta.

d. Kebutuhan penghargaan (eksterens needs)

e. Kebutuhan aktualisasi diri (self-actualization needs)

\section{Upaya-Upaya Memotivasi Karyawan} berikut:

Menurut Ishak (2009), cara memotivasi karyawan dapat dilakukan sebagai

a. Rasa hormat (respect) yaitu memberikan rasa hormat dan penghargaan secara adil bukan berati sama.

b. Informasi, yaitu dengan memberikan informasi kepada karyawan mengenai aktivitas organisasi, terutama tentang apa yang harus di lakukan dan bagaimana melakukannya.

c. Perilaku, usahakanlan mengubah perilaku sesuai dengan harapan bawahan.

d. Hukuman, berikan hukuman kepada karyawan yang bersalah di ruangan yang terpisah, jangan menghukum di depan karyawan lain karena dapat menimbulkan frustasi dan merendahkan martabat.

e. Perasaan, tanpa mengetahui bagaimana harapan karyawan dan perasaan apa yang ada dalam diri mereka, sangat sulit bagi pemimpin untuk memotivasi bawahan. 


\section{Pengertian Pengalaman Kerja}

Johson (2007:228), menyatakan bahwa: "Pengalaman memunculkan potensi seseorang. Potensi penuh akan muncul bertahap seiring berjalannya waktu sebagai tanggapan terhadap bermacam-macam pengalaman". Pengalaman kerja tidak menyangkut jumlah masa kerja, tetapi lebih dari memperhitungkan jenis pekerjaan yang sering atau pernah di hadapi. Sejalan dengan bertambahnnya pekerjaan, maka akan sering bertambah pula pengetahuan dan keterampilan seseorang dalam bekerja.

\section{Faktor-faktor yang Mempengaruhi Pengalaman Kerja}

Menurut Foster, (2011), ada beberapa hal untuk menentukan berpengalaman tidaknya seorang karyawan sekaligus sebagai indikator pengalaman kerja yaitu:

a. Lama waktu atau masa kerja

b. Tingkat pengetahuan dan keterampilan yang dimiliki

c. Penguasaan terhadap pekerjaan dan peralatan

\section{Pengukuran Pengalaman Kerja}

Pengukuran pengalaman kerja sebagai sarana untuk menganalisa dan mendorong efisiensi dalam melaksanakan tugas pekerjaan. Menurut Asri, (2006 : 131), ada beberapa hal untuk mengukur pengalaman kerja seseorang yaitu :

a. Gerakannya mantap dan lancar

b. Gerakannya berirama

c. Lebih cepat menanggapi tanda-tanda

d. Dapat menduga akan timbulnya kesulitan sehingga lebih siap menghadapinya

e. Bekerja dengan tenang

\section{Cara Memperoleh Pengalaman Kerja}

Syukur (2011:83), menyatakan bahwa "cara yang dapat dilaksanakan untuk memperoleh pengalaman kerja adalah melalui pendidikan, pelaksanaan tugas, media informasi, penataran, pergaulan, dan pengamatan”. Penjelasannya :
a. Pendidikan
b. Melaksanakan tugas
c. Media informasi
d. Penataran
e. Pergaulan
f. Pengamatan

\section{Pengertian Kinerja Karyawan}

Landasan yang sesungguhnnya dalam suatu organisasi adalah kinerja. Jika tidak ada kinerja maka seluruh bagian organisasi tidak tercapai tujuannya. Kinerja perlu dijadikan bahan evaluasi untuk manajer dan pemimpin. Dalam kamus besar bahasa Indonesia (2006: 63), mengatakan bahwa kinerja adalah sesuatu yang dicapai, prestasi yang diperlihatkan dan kemampuan kerja. 


\section{Faktor-faktor kinerja karyawan} antara lain:

Menurut Nitisemito (2011:109), terdapat berbagai faktor kinerja karyawan,

a. Jumlah dan komposisi dari kompensasi yang diberikan

b. Penempatan kerja yang tepat

c. Pelatihan dan promosi

d. Rasa aman di masa depan (dengan adanya pesangon dan sebagainya)

e. Hubungan dengan rekan kerja

f. Hubungan dengan pemimpin

\section{Standar Kinerja Karyawan}

Menurut Wirawan (2009 : 97),"Standar kinerja adalah target, sasaran, tujuan upaya kerja karyawan dalam kurun waktu tertentu". Dalam melaksanakan pekerjaannya, karyawan harus mengarahkan semua tenaga, pikiran, keterampilan, pengetahuan dan waktu kerja untuk mencapai apa yang di tentukan oleh standar kinerja.

\section{Hipotesis Penelitian}

Hipotesis penelitian ini adalah :

$\mathrm{H}_{1}$ : Secara parsial, variabel motivasi karyawan berpengaruh signifikan terhadap kinerja karyawan pada PT. Perkebunan Nusantara II (Persero) Tanjung Morawa.

$\mathrm{H}_{2}$ : Secara parsial, variabel pengalaman kerja berpengaruh signifikan terhadap kinerja karyawan pada PT. Perkebunan Nusantara II (Persero) Tanjung Morawa.

$\mathrm{H}_{3}$ : Secara simultan, variabel motivasi dan pengalaman kerja karyawan berpengaruh signifikan terhadap kinerja karyawan pada PT. Perkebunan Nusantara II (Persero) Tanjung Morawa.

\section{METODE PENELITIAN}

\section{Jenis Penelitian}

Dalam penelitian ini jenis penelitian yang digunakan adalah penelitian kuantitatif yang bersifat korelasi. "Metode korelasi yaitu, suatu penelitian untuk mengetahui hubungan dan tingkat hubungan antara dua variabel atau lebih tanpa ada upaya untuk mempengaruhui variabel tersebut sehingga tidak terdapat manipulasi variabel”. (Fraenkel dan Wellen, 2008 : 328)

\section{Tehnik Analisis Data Penelitian \\ Analisis Regresi Linier Berganda}

Metode Analisis regresi linier berfungsi untuk mengetahui pengaruh atau hubungan antara variabel independen (motivasi dan pengalaman kerja) dan variabel dependen (kinerja karyawan) akan digunakan analisis regresi linier berganda (multiple regression analiysis). Penelitian menggunakan bantuan program software SPSS untuk memperoleh hasil yang lebih terarah. Rumusan perhitungan persamaan regresi berganda adalah sebagai berikut:

$\mathbf{Y}=\mathbf{a}+\mathbf{b}_{1} \mathbf{X}_{1}+\mathbf{b}_{2} \mathbf{X}_{2+e}$ 


\section{Uji Hipotesis}

\section{Uji-t}

Uji t menunjukkan seberapa besar pengaruh variabel secara individual terhadap variabel terikat.

\section{Uji-F}

Uji-F pada dasarnya menunjukkan apakah semua variabel bebas yang dimasukkan dalam model mempunyai pengaruh secara bersama-sama terhadap variabel terikat.

\section{Koefisien Determinasi $\left(\mathbf{R}^{\mathbf{2}}\right)$}

Koefisien Determinasi $\left(\mathrm{R}^{2}\right)$ pada intinnya mengukur seberapa kemampuan model dalam menerangkan variabel terikat. Jika $\mathrm{R}^{2}$ semakin besar (mendekati satu), maka dapat dikatakan bahwa hubungan variabel bebas $\left(\mathrm{X}_{1}\right.$ dan $\left.\mathrm{X}_{2}\right)$ adalah besar terhadap variabel terikat (Y). Hal ini berarti model yang di gunakan semakin kuat untuk menerangkan hubungan variabel bebas yang diteliti terhadap variabel terikat.

\section{HASIL DAN PEMBAHASAN \\ Hasil Penelitian \\ Pengujian Kualitas Data \\ Uji Validitas Data}

Hasil Uji Validitas Variabel $\mathrm{X}_{1}$ (Motivasi)

\begin{tabular}{|c|c|c|c|}
\hline Pernyataan & $\mathrm{r}_{\text {hitung }}$ & $\mathrm{r}_{\text {tabel }}$ & Validitas \\
\hline Butir 1 & 0.439 & 0,220 & Valid \\
\hline Butir 2 & 0.252 & 0,220 & Valid \\
\hline Butir 3 & 0.281 & 0,220 & Valid \\
\hline Butir 4 & 0.526 & 0,220 & Valid \\
\hline Butir 5 & 0.409 & 0,220 & Valid \\
\hline Butir 6 & 0.436 & 0,220 & Valid \\
\hline
\end{tabular}

Hasil Uji Validitas Variabel $\mathrm{X}_{2}$ (Pengalaman kerja)

\begin{tabular}{|c|c|c|c|}
\hline Pernyataan & $r_{\text {hitung }}$ & $r_{\text {tabel }}$ & Validitas \\
\hline Butir 1 & 0.606 & 0,220 & Valid \\
\hline Butir 2 & 0.567 & 0,220 & Valid \\
\hline Butir 3 & 0.536 & 0,220 & Valid \\
\hline
\end{tabular}

Hasil Uji Validitas Y (Kinerja karyawan)

\begin{tabular}{|c|c|c|c|}
\hline Pernyataan & $\mathrm{r}_{\text {hitung }}$ & $\mathrm{r}_{\text {tabel }}$ & Validitas \\
\hline Butir 1 & 0.330 & 0,220 & Valid \\
\hline Butir 2 & 0.239 & 0,220 & Valid \\
\hline Butir 3 & 0.337 & 0,220 & Valid \\
\hline Butir 4 & 0.397 & 0,220 & Valid \\
\hline Butir 5 & 0.420 & 0,220 & Valid \\
\hline Butir 6 & 0.371 & 0,220 & Valid \\
\hline
\end{tabular}




\section{Uji Reliabilitas}

Hasil Uji Reliabilitas Variabel

\begin{tabular}{|l|c|c|c|}
\hline \multicolumn{1}{|c|}{ Variabel } & Jumlah Pertanyaan & Cronbach's Alpha & Keterangan \\
\hline Kinerja karyawan $(\mathrm{Y})$ & 6 & 0.618 & Reliable \\
\hline Motivasi $\left(\mathrm{X}_{1}\right)$ & 6 & 0.659 & Reliable \\
\hline Pengalaman kerja $\left(\mathrm{X}_{2}\right)$ & 3 & 0.743 & Reliable \\
\hline
\end{tabular}

\section{Pengujian Asumsi Klasik}

\section{Pengujian Normalitas Data}

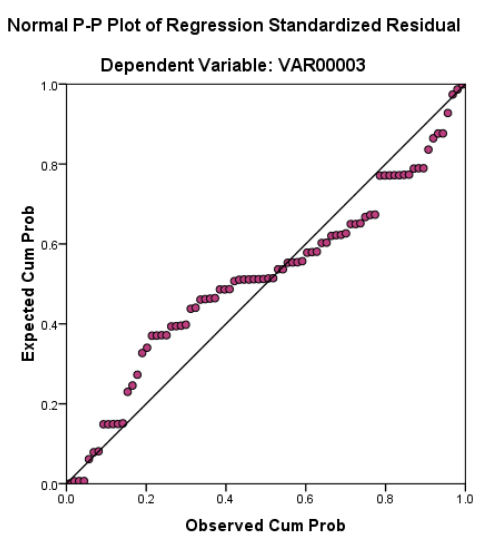

Dari gambar grafik di atas, dapat diketahui bahwa titik-titik menyebar sekitar garis dan mengikuti garis diagonal maka nilai residual telah normal.

Salah satu cara lain untuk melihat normalitas adalah menggunakan Kolmogorov Smirnov.

One-Sample Kolmogorov-Smirnov Test

\begin{tabular}{|ll|r|}
\hline & & Unstandardized Residual \\
\hline $\mathrm{N}$ & & 82 \\
Normal Parameters $^{\mathrm{a}}$ & Mean & .0000000 \\
& Std. Deviation & 2.76532564 \\
Most Extreme & Absolute & .161 \\
Differences & Positive & .110 \\
& Negative & -.161 \\
Kolmogorov-Smirnov Z Z & 1.462 \\
Asymp. Sig. (2-tailed) & .278 \\
\hline \multicolumn{2}{|l|}{ a. Test distribution is Normal. } & \\
\cline { 2 - 2 }
\end{tabular}

Berdasarkan output di atas, diketahui bahwa nilai signifikansi nilai asymp.sig sebesar 0.278 lebih besar dari 0,05, sehingga dapat disimpulkan bahwa data yang diuji berdistribusi normal. 


\section{Pengujian Multikolinieritas}

Hasil Uji Multikolinearitas

\begin{tabular}{|c|l|c|c|}
\hline \multicolumn{2}{|c|}{ Model } & \multicolumn{2}{c|}{ Collinearity Statistics } \\
\cline { 3 - 4 } & Tolerance & VIF \\
\hline 1 & Motivasi & .936 & 1.068 \\
2 & Pengalaman kerja & .936 & 1.067 \\
\hline
\end{tabular}

a. Dependent Variable : kinerja karyawan

a. Nilai VIF dari nilai motivasi dan pengalaman kerja lebih kecil atau dibawah 5 (VIF < 5), ini berarti tidak terkena multikolenearitas antara variabel independen dalam model regresi.

b. Nilai Tolerance dari nilai motivasi dan pengalaman kerja lebih besar dari 0,1 ini berarti tidak terdapat multikolinearitas antar variabel independen dalam model regresi.

\section{Pengujian Heteroskedastisitas}

Scatterplot

Dependent Variable: VAR00003

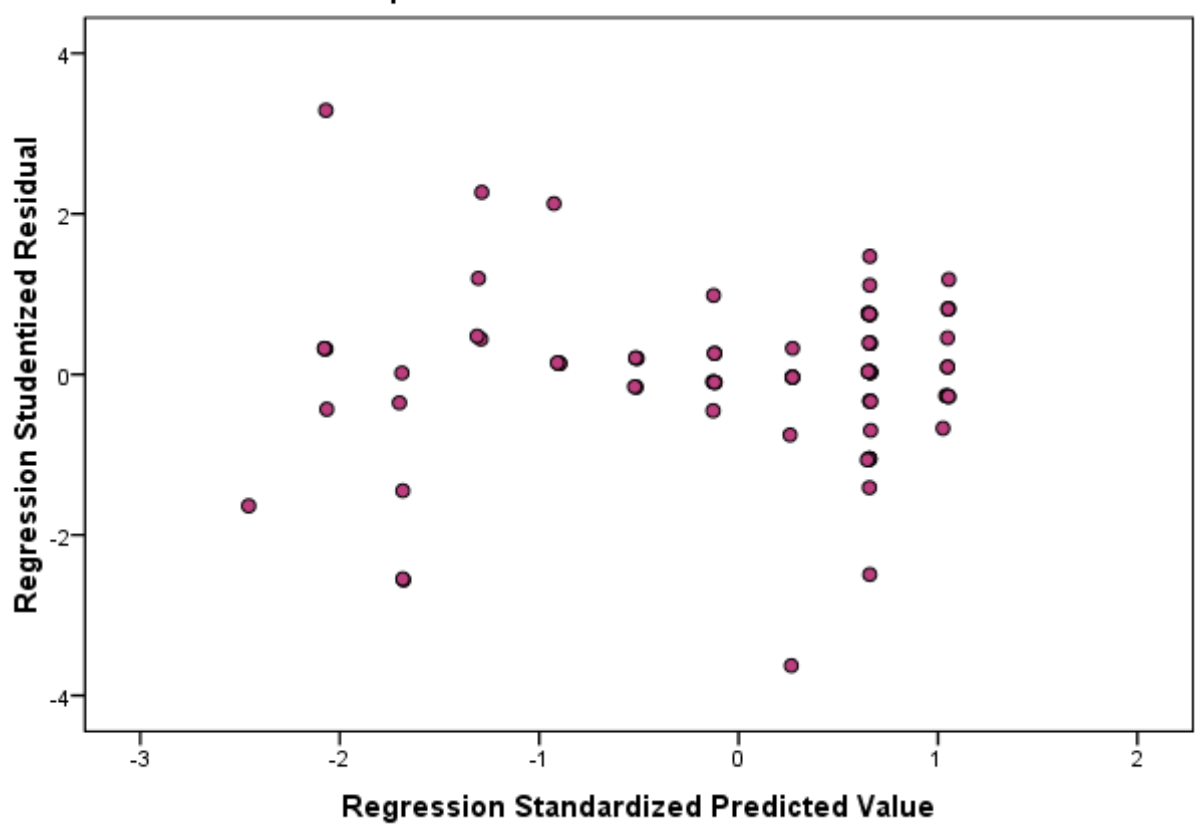

Berdasarkan Gambar, dapat terlihat bahwa tdak ada pola yang jelas, serta titik-titik menyebar di atas dan di bawah angka 0 pada sumbu $\mathrm{Y}$, maka berdasarkan metode grafik tidak terjadi heteroskedastisitas pada model regresi. 
Uji Regresi Linier Berganda

Coefisients

\begin{tabular}{|c|r|r|r|r|r|}
\hline \multirow{2}{*}{ Model } & \multicolumn{1}{|c|}{$\begin{array}{c}\text { Unstandardized } \\
\text { Coefisients }\end{array}$} & & \multicolumn{1}{|c|}{$\begin{array}{c}\text { Standardized } \\
\text { Coefisients }\end{array}$} & \multirow{2}{*}{ t } & \multirow{2}{*}{ Sig } \\
\cline { 2 - 6 } & \multicolumn{1}{|c|}{$\mathrm{B}$} & Std. Error & \multicolumn{1}{|c|}{ Beta } & & \\
\hline (Constant) & 14,249 & 2,785 & & 5,116 &, 000 \\
$\mathrm{X}_{1}$ &, 004 &, 105 &, 004 &, 042 &, 966 \\
$\mathrm{X}_{2}$ &, 825 &, 126 &, 607 & 6,573 &, 000 \\
\hline
\end{tabular}

$$
\mathrm{Y}=14,249+0,004 \mathrm{X}_{1}+0,825 \mathrm{X}_{2}
$$

a. $b_{1}=0,004$, artinya variabel $\mathrm{X}_{1}$ (motivasi) bertanda positif berarti setiap terjadi perubahan motivasi yang lebih baik akan meningkatkan kinerja karyawan pada PT. Bintang Utama Motor.

b. $\mathrm{b}_{2}=0,825$, artinya variabel $\mathrm{X}_{2}$ (pengalaman kerja) bertanda positif berarti setiap terjadi perubahan pengalaman kerja yang lebih baik akan meningkatkan kinerja karyawan pada PT. Bintang Utama Motor.

\section{Uji Hipotesis}

\section{Hasil Uji t}

\section{Hasil Uji t}

\begin{tabular}{|l|r|c|}
\hline \multicolumn{1}{|c|}{ Model } & \multicolumn{1}{c|}{$\mathbf{t}$} & \multicolumn{1}{c|}{ Sig } \\
\hline (Constant) & 5,116 &, 000 \\
Motivasi $\left(\mathrm{X}_{1}\right)$ &, 042 &, 966 \\
Pengalaman Kerja $\left(\mathrm{X}_{2}\right)$ & 6,573 &, 000 \\
\hline
\end{tabular}

Secara parsial motivasi $\left(\mathrm{X}_{1}\right)$ berpengaruh akan tetapi tidak signifikan terhadap kinerja karyawan $(0,966>0.05)$. Secara parsial pengalaman kerja $\left(\mathrm{X}_{2}\right)$ berpengaruh signifikan terhadap kinerja karyawan $(0,000<0.05)$.

\section{Hasil Uji F}

Tabel 11.

Anova

\begin{tabular}{|l|c|c|c|c|c|}
\hline \multicolumn{1}{|c|}{ Model } & $\begin{array}{c}\text { Sum of } \\
\text { Squares }\end{array}$ & Df & $\begin{array}{c}\text { Mean } \\
\text { Square }\end{array}$ & F & Sig \\
\hline Regression & 363,042 & 2 & 181,521 & 23,151 &, 000 \\
Residual & 619,409 & 79 & 7,841 & & \\
\hline Total & $\mathbf{9 8 2 , 4 5 1}$ & $\mathbf{8 1}$ & & & \\
\hline
\end{tabular}

Probabilitas $=0,000$, tingkat kesalahan $\alpha 5 \%$. Probabilitas lebih kecil yaitu $0,000<0.05$ maka $\mathrm{H}_{\mathrm{i}}$ diterima. Artinya variabel motivasi $\left(\mathrm{X}_{1}\right)$ dan pengalaman kerja $\left(\mathrm{X}_{2}\right)$ secara bersama-sama atau simultan berpengaruh signifikan terhadap kinerja karyawan (Y). 
Koefisien Determinasi $\left(\mathbf{R}^{2}\right)$

Tabel IV.12.

Model Summary

\begin{tabular}{|c|c|c|c|c|}
\hline Model & R & R Square & $\begin{array}{c}\text { Adjusted R } \\
\text { Square }\end{array}$ & $\begin{array}{c}\text { Std. Error of the } \\
\text { Estimate }\end{array}$ \\
\hline 1 &, 608 &, 370 &, 354 & 2,80011 \\
\hline
\end{tabular}

Berdasarkan hasil analisis regresi di atas, diketahui nilai koefisien determinasi sebesar 0,370. Nilai koefisien determinasi sebesar $37 \%$ menunjukkan bahwa motivasi $\left(\mathrm{X}_{1}\right)$ dan pengalaman kerja $\left(\mathrm{X}_{2}\right)$ sebagai variabel independent mampu menjelaskan variabel kinerja karyawan, sedangkan sisanya sebesar $63 \%$ dijelaskan oleh faktor-faktor lain yang tidak dimasukkan dalam penelitian ini.

\section{Pembahasan \\ Pengaruh Motivasi Kerja Terhadap Kinerja Karyawan}

Motivasi kerja menjadi hal yang penting bagi setiap perusahaan, terutama manfaat bagi karyawan dan perusahaan. Motivasi akan mendorong karyawan untuk lebih berprestasi dan produktif. Begitu pula motivasi dalam perusahaan dalam rangka peningkatan kinerja dan penekanan biaya melalui perbaikan sikap dan tingkah laku karyawan. Jadi, motivasi dapat di simpulkan bahwa motivasi merupakan satu upaya yang dilakukan untuk mendorong karyawan dalam mencapai satu tujuan dalam organisasi yang dimana karyawan atau pekerja yang akan melakukan suatu tindakan untuk mencapai tujuan yang maksimal dalam perusahaan.

Menurut Mangkunegara (2013), motif merupakan suatu dorongan kebutuhan dalam diri pegawai yang perlu dipenuhi agar pegawai tersebut dapat menyesuaikan diri terhadap lingkungannya, sedangkan motivasi adalah kondisi yang menggerakkan pegawai agar mampu mencapai tujuan dari motifnya. Dari hasil regresi secara parsial dapat dinyatakan bahwa motivasi berpengaruh tetapi tidak signifikan terhadap kinerja karyawan. Hal ini relevan dengan penelitian terdahulu yang dilakukan oleh Muhibbang (2014), yang menyatakan bahwa motivasi berpengaruh terhadap produktivitas kerja akan tetapi tidak signifikan.

Hal ini dikarenakan pekerjaan yang dilakukan monoton sehingga menyebabkan karyawan menjadi lebih cepat bosan dan jenuh, masih adanya perbedaan gaji yang diterima antara karyawan dengan karyawan lainnya disebabkan kedekatan hubungan dengan pimpinan, hubungan yang kurang harmonis disebabkan adanya jarak antara pimpinan dengan bawahan serta kondisi kerja yang kurang kondusif.

\section{Pengaruh Pengalaman Kerja Terhadap Kinerja Karyawan}

Pengalaman dalam suatu kegiatan sangat di perlukan, karena eksperiance is the teacher (pengalaman adalah guru yang terbaik). Maksud dari hal tersebut adalah bahwa seseorang belajar dari dari pengalaman yang telah dialaminya. Dapat disimpulkan bahwa pengalaman kerja seseorang menunjukkan jenis-jenis pekerjaan yang telah di lakukan seseorang dan memberikan peluang besar bagi seseorang untuk melakukan pekerjaan yang lebih baik. Karena semakin luas pengalaman kerja seseorang dalam melakukan pekerjaan dan semakin sempurna 
pula pola pikir dan sikapnya dalm bertindak atau mencapai tujuan yang telah di tetapkan.

Johson (2007:228), menyatakan bahwa: "Pengalaman memunculkan potensi seseorang. Potensi penuh akan muncul bertahap seiring berjalannya waktu sebagai tanggapan terhadap bermacam-macam pengalaman”. Pengalaman kerja tidak menyangkut jumlah masa kerja, tetapi lebih dari memperhitungkan jenis pekerjaan yang sering atau pernah di hadapi. Sejalan dengan bertambahnnya pekerjaan, maka akan sering bertambah pula pengetahuan dan keterampilan seseorang dalam bekerja.

Dari hasil regresi secara parsial dapat dinyatakan bahwa pengalaman kerja berpengaruh terhadap kinerja karyawan. Berarti hal ini sesuai dengan penyebaran kuisioner yang menyatakan bahwa pengetahuan dan keterampilan mendukung kinerja karyawan dalam menyelesaikan pekerjaannya serta masa kerja dapat meningkatkan kemampuan karyawan dalam bekerja.

\section{Pengaruh Motivasi Kerja dan Pengalaman Kerja Terhadap Kinerja Karyawan}

Dari hasil uji regresi secara simultan diperoleh hasil bahwa motivasi dan pengalaman kerja berpengaruh signifikan. Hal ini menunjukkan bahwa kuisioner yang disebarkan sudah cocok dan sesuai dengan keinginan responden sehingga hasilnya lebih valid lagi. Kuisioner yang disebarkan antara lain adalah motivasi dapat menciptakan profesionalisme dalam bekerja, pemberian penghargaan merupakan bentuk apresiasi perusahaan terhadap motivasi kerja serta karyawan memanfaatkan waktu yang luang untuk terus berkarya.

PT. Perkebunan Nusantara (Persero) II Tanjung Morawa bergerak dibidang usaha pertanian dan perkebunan. Untuk itu motivasi dalam bekerja menjadi sangat penting bagi perusahaan agar hasil yang diperoleh benar-benar telah maksimal untuk kepentingan perusahaan. Hal ini dikarenakan kuantitas kerja yang dihasilkan melebihi target yang dibebankan perusahaan kepada karyawan, adanya penyerapan ilmu pengetahuan dari pimpinan kepada bawahan bagaimana cara bekerja yang efektif dan efisien, adanya kreatifitas karyawan ketika dalam bekerja serta karyawan mampu menyelesaikan pekerjaan secara tepat waktu sesuai dengan keinginan dan tujuan perusahaan.

\section{SIMPULAN DAN SARAN Simpulan}

Dari hasil penelitian tentang pengaruh motivasi dan pengalaman kerja terhadap kinerja pada Kantor Direksi PT. Perkebunan Nusantara II (Persero) Tanjung Morawa, maka dapat ditarik kesimpulan sebagai berikut :

1. Dari hasil uji regresi dinyatakan bahwa secara parsial motivasi $\left(\mathrm{X}_{1}\right)$ berpengaruh tetapi tidak signifikan terhadap kinerja karyawan (Y).

2. Dari hasil uji regresi dinyatakan bahwa secara parsial pengalaman kerja $\left(\mathrm{X}_{2}\right)$ berpengaruh positif dan signifikan terhadap kinerja karyawan (Y).

3. Dari hasil uji regresi dinyatakan bahwa variabel motivasi $\left(\mathrm{X}_{1}\right)$ dan pengalaman kerja $\left(\mathrm{X}_{2}\right)$ secara bersama-sama atau serentak berpengaruh positif dan signifikan terhadap kinerja karyawan (Y). 
4. Nilai koefisien determinasi sebesar $37 \%$ menunjukkan bahwa motivasi $\left(\mathrm{X}_{1}\right)$ dan pengalaman kerja $\left(\mathrm{X}_{2}\right)$ sebagai variabel independent mampu menjelaskan variabel kinerja karyawan (Y), sedangkan sisanya sebesar $63 \%$ dijelaskan oleh faktor-faktor lain yang tidak dimasukkan dalam penelitian ini.

\section{Saran}

1. Sebaiknya motivasi benar-benar diperhatikan karena hal ini mau tidak mau sangat mempengaruhi pola pikir dan cara kerja yang dilakukan oleh karyawan. Semakin rendah motivasinya maka semakin rendah pula kinerjanya. Jadi sebaiknya karyawan perlu melihat secara langsung bagaimana kinerja karyawan sesungguhnya, dan tidak hanya berdasarkan laporan yang diterima saja dari wakilnya atau pembisiknyta.

2. Pengalaman kerja memang sangat benar-benar dibutuhkan dalam meningkatkan kinerja perusahaan secara keseluruhan. Akan tetapi apabila pengalaman kerja tersebut tidak dibarengi dengan ilmu pengetahuan yang memadai, maka hal ini akan menjadi percuma karena untuk peningkatan karirnya akan menjadi terhambat. Untuk itulah top manajemen harus memperhatikan karyawan mana saja yang layak untuk ditingkatkan jenjang karirnya atau pendidikannya agar bisa mempengaruhi produktivitas kerja perusahaan.

3. Untuk perusahaan secara keseluruhan sangat penting hasil dari penelitian ini dimana hasil yang diperoleh bisa menjadi suatu bahan acuan untuk menerapkan sistem yang sama dan pola yang sama akan tetapi berbeda dalam hal penanganan kepada karyawan. Hal ini lah yang mungkin bisa dijadikan patokan bagi perusahaan untuk meningkatkan kinerja karyawan lebih maksimal lagi.

\section{DAFTAR PUSTAKA}

Arikunto, Suharsimi. 2007, Manajemen Penelitian, Jakarta. Rineka Cipta.

Asri, Marwan, 2006. Pengelolaan Karyawan, Yogyakarta BPFE-Yogyakarta.

Elaine, B. 2007. Contextual Teaching and Learning. Cetakan Ketiga. Penerbit: MLC.

Foster, B.S. \& Karen, R. 2011. Pembinaan Untuk Meningkatkan Kinerja Karyawan. Jakarta: PPN.

Fuad, Mas'ud. 2004, Survei Diagonis Organisasional : Konsep Dan Aplikasi. Program Magister Manajemen, Universitas Diponogoro. Semarang, Badan Penerbit Universitas Diponogoro.

Hasibuan, Malayu, SP., 2012, Manajemen Sumber Daya Manusia, Edisi Revisi, Jakarta. Bumi Aksara.

Ishak, Arep. 2009. Manajemen Motivasi.Jakarta: PT. Grasindo.

Johson, 2007, Pengukuran Kinerja Berbasis Kompetensi, Jakarta : Ghalia Indonesia.

Kadji, Y. 2012. Tentang Teori Maslow. No.1. Vol 9. Jurnal Inovasi Online. 
Luthans, Fred. 2006. Perilaku Organisasi, Edisi Sepuluh, Yogyakarta, Penerbit Andi.

Mangkunegara, Anwar Prabu. 2013. Manajemen Sumber Daya Manusia Perusahaan, Bandung: PT Remaja Rosdakarya.

Muhibbang, 2014, Pengaruh Motivasi Dan Pengalaman Kerja Terhadap Produktivitas Kerja Karyawan Pada PT. Bosowa Berlian Motor Makasar

Nano, Ismanto, 2005, Pengaruh Pengalaman Kerja Dan Disiplin Kerja Terhadap Produktivitas Kerja Karyawan Perusahaan Speaker Aktif Arofah Eelektrinik di Desa Gribik Kec. Gebong Kab.Kudus

Nawawi, Hadari, 2006, Evaluasi Dan Manajemen Kinerja Dilingkungan Perusahaan Dan Industri, Yogyakarta : Gajah Mada University Press

Nitisemito, Alex Somadji, 2011, Manajemen Personalia, Jakarta : Ghalia Indonesia

Noor, Juliansyah. 2011. Metodologi Penelitian, Jakarta: Kencana Prenanda Media Group

Robbins. 2007. Perilaku Organisasi. Jilid Satu. Jakarta: Prenhalindo.

Safari, T. 2006. Kepemimpinan. Edisi Pertama. Yogyakarta: Graha Ilmu.

Siagian, Sondang P. 2012 Kiat Meningkatkan Produktivitas Kerja. Jakarta: Rineka Cipta

Situmorang, Syafrizal Helmi et al, 2011. Analisis Data Untuk Riset Manajemen dan Bisnis, USU Press, Medan

Soewadji, Jusuf. 2012. Pengantar Metodologi Penelitian. Jakarta, Mitra Wicana Media

Sri Purwanti, 2010, Pengaruh Motivasi Kerja Karyawan Terhadap Kinerja Karyawan PT. Anindya Mitra Iinternasional

Stephan, P. And Mary Coulter. 2009. Manajemen Sumber Daya Manusia. Jilid Satu. Edisi Kedelapan. Jakarta Barat: Indeks.

Syukur. 2011. Metode Penelitian Dan Penyajian Data Pendidikan, Semarang: Medya Wiyata

Wirawan. 2009 Evaluasi Kerja Sumber Daya Manusia “Teori, Aplikasi dan Penelitian” Jakarta, Salemba Empat. 